Silva, LM \& Ciasca, MIFL (2020). School physical structure as a determinant of quality in education in professional schools in Ceará: between reality and myth. Research, Society and Development, 9(7): 1-20, e642974634.

\title{
Estrutura física escolar como fator determinante da qualidade na educação em escolas profissionais do Ceará: entre a realidade e o mito
}

\section{School physical structure as a determinant of quality in education in professional schools in Ceará: between reality and myth \\ La estructura física escolar como determinante de la calidad de la educación en las escuelas profesionales de Ceará: entre la realidad y el mito}

Recebido: 17/05/2020 | Revisado: 18/05/2020 | Aceito: 22/05/2020 | Publicado: 30/05/2020

\section{Lucas Melgaço da Silva}

ORCID: https://orcid.org/0000-0003-4145-4036

Prefeitura Municipal de Maracanaú, Brasil

E-mail: lucasmelgaco@alu.ufc.br

Maria Isabel Filgueiras Lima Ciasca

ORCID: https://orcid.org/0000-0002-9166-8887

Universidade Federal do Ceará, Brasil

E-mail: isabelfil@uol.com.br

\section{Resumo}

O acesso às boas condições estruturais escolares é apontado por agentes educacionais como essencialmente importante ao desempenho das funções pedagógicas na oferta do ensino. Muitas vezes são tratadas como fatores determinantes à qualidade ensino e na definição do fracasso ou sucesso escolar do aluno. Considerando que o Estado do Ceará aparece no cenário nacional como referência de qualidade educacional, em especial, com alusão à política de educação profissional integrada ao ensino médio, o objetivo desta pesquisa foi avaliar se a estrutura física predial, bem como os recursos didático-pedagógicos disponíveis são fatores determinantes para qualidade na educação nesta modalidade de ensino. Trata-se de um trabalho de natureza qualitativa, de cunho descritivo, feito por meio de levantamento bibliográfico, pesquisa documental, observação in loco e aplicação de questionário, na forma de estudo comparativo entre 10 Escolas Estaduais de Educação Profissional (EEEP), sendo 5 com alto rendimento e 5 com baixo rendimento, nos resultados das avaliações do Sistema Permanente de Avaliação da Educação Básica do Estado do Ceará (SPAECE). O estudo 
descarta o fator estrutura física, porém, de forma isolada, como fator determinante da oferta da educação de qualidade, bem como propulsor do sucesso escolar, que considera resultados de avaliações externas. Ademais, se apresenta como contribuição à formação acadêmica, científica e profissional, ao tempo que concebe aportes teóricos à construção de novas pesquisas de melhoria da aprendizagem estudantil.

Palavras-chave: Qualidade na educação; Estrutura física; Educação profissional; Ceará.

\begin{abstract}
Access to selected good conditions is indicated by educational agents as essential for the performance of pedagogical functions in the provision of education. They are often treated as determining factors for the quality of teaching and the definition of elementary education or the student's academic success. What the State of Ceará shows in the national scenario as a reference for educational quality, in particular, with reference to the professional education policy integrated with high school, or the objective of this research was to evaluate whether the physical structure of the building, as well as the didactic resources- Pedagogical factors are available that determine the quality of education in this type of teaching. It is a qualitative work, of a descriptive nature, done through bibliographic survey, documentary research, observation on the spot and application of a questionnaire, in the form of a comparative study between 10 State Schools of Professional Education (EEEP), being 5 with high performance and 5 with low performance, in the results of the evaluations of the Permanent System of Evaluation of Basic Education of the State of Ceará (SPAECE). The study discards the factor of physical structure, however, in isolation, as a determining factor in the provision of quality education, as well as a driver of school success, which considers the results of external evaluations. In addition, it presents as a contribution to academic, scientific and professional training, while conceiving the theoretical topics in the construction of new research to improve student learning.
\end{abstract}

Keywords: Quality in education; Physical structure; Professional education; Ceará.

\title{
Resumen
}

El acceso a las buenas condiciones seleccionadas está indicado por los agentes educativos como esenciales para el desempeño de las funciones pedagógicas en la provisión de educación. A menudo son tratados como factores determinantes para la calidad de la enseñanza y la definición de la educación primaria o el éxito académico del estudiante. Lo que el Estado de Ceará muestra en el escenario nacional como referencia para la calidad 
educativa, en particular, con referencia a la política de educación profesional integrada en la escuela secundaria, o el objetivo de esta investigación fue evaluar si la estructura física del edificio, así como los recursos didácticos. Existen factores pedagógicos que determinan la calidad de la educación en este tipo de enseñanza. Es un trabajo cualitativo, de carácter descriptivo, realizado mediante encuesta bibliográfica, investigación documental, observación sobre el terreno y aplicación de un cuestionario, en forma de estudio comparativo entre 10 Escuelas Estatales de Educación Profesional (EEEP), siendo 5 con alto desempeño y 5 con bajo desempeño, en los resultados de las evaluaciones del Sistema Permanente de Evaluación de la Educación Básica del Estado de Ceará (ESPAÑA). El estudio descarta el factor de la estructura física, sin embargo, de forma aislada, como un factor determinante en la provisión de una educación de calidad, así como un impulsor del éxito escolar, que considera los resultados de las evaluaciones externas. Además, se presenta como una contribución a la formación académica, científica y profesional, al tiempo que concibe los temas teóricos en la construcción de nuevas investigaciones para mejorar el aprendizaje de los estudiantes.

Palabras clave: Calidad en la educación; Estructura física; Educación professional; Ceará.

\section{Introdução}

Nos últimos anos, o Estado do Ceará aparece no cenário nacional como referência na oferta educacional de qualidade, considerando os principais indicadores e resultados oriundos de avaliações externas. Esse status quo é alavancado, principalmente, pela política de educação profissional integrada ao ensino médio, implantada no estado a partir de 2008 . No estudo intitulado "Excelência com Equidade no Ensino Médio: a dificuldade das redes de ensino para dar um suporte efetivo às escolas”, publicado em 2019 e realizado pela Fundação Lemann, Interdisciplinaridade e Evidências no Debate Educacional (Iede), Instituto Unibanco e Itaú BBA, apontou que 55 de 100 instituições que atendem alunos de baixa renda e se destacaram no Exame Nacional do Ensino Médio (ENEM) e na Prova Brasil, estão localizadas no Ceará. Destas, 54 são Escolas Profissionais de Educação Profissional (EEEP's).

Para o alcance da qualidade, a educação pondera o diagnóstico de diferentes aspectos que podem interferir nos meios de construção de uma escola de qualidade (Dourado \& Oliveira, 2009). No meio acadêmico é muito comum encontrarmos estudos que investigam esses fatores e relacionam a deficiência da estrutura física e material das instituições escolares à elementos primordiais de interferência na efetivação dessa qualidade. Para Kimura (2008, p. 
(CC BY 4.0) | ISSN 2525-3409 | DOI: http://dx.doi.org/10.33448/rsd-v9i7.4634

20), o acesso às boas condições estruturais é apontado por agentes educacionais como essencialmente importante ao desempenho das funções pedagógicas do ensino.

Com base nisso, o artigo ora apresentado surgiu a partir do seguinte questionamento: fatores relacionados à estrutura física escolar são determinantes da eficácia e da qualidade na educação ofertada pelas EEEP's do Ceará?

A fim de responder o questionamento acima, o objetivo deste texto foi avaliar, por meio de um estudo comparativo entre 10 EEEP's, sendo 5 com alto rendimento e 5 com baixo rendimento, considerando os resultados das avaliações realizadas no âmbito do Sistema Permanente de Avaliação da Educação Básica do Estado do Ceará (SPAECE ${ }^{1}$ ), se a estrutura física predial, bem como os recursos didático-pedagógicos são fatores determinantes para qualidade na educação.

O estudo se propõe a contribuir com a eficácia e equidade na oferta da educação, de modo a cooperar com a melhoria dos resultados nas avaliações externas de escolas que, por algum motivo, possuem dificuldades de se firmarem como instituições de referência na oferta do ensino.

\subsection{A estrutura física escolar como meio de alcance da qualidade na oferta do ensino}

A melhoria da oferta da educação é uma busca constante dos sistemas de ensino, sejam eles nacionais, estaduais ou municipais. De acordo com o Artigo $3^{\circ}$, inciso IX, da Lei de Diretrizes e Bases da Educação Nacional (LDB) nº 9.394/96, o ensino será ministrado tendo como base a garantia de padrão de qualidade (Brasil, 1996). Esse, só será efetivado por meio de práticas capazes de proporcionar progressos significativos quanto ao desempenho dos alunos.

Segundo Vieira \& Vidal (2010, p. 5), essas melhorias são resultados de fatores associados à relação escola-comunidade, ambiente organizado e, seguro, bom clima escolar, trabalho coletivo, gestão democrática e participativa, liderança do atual diretor, expectativas positivas, metas de aprendizagens definidas e expectativas positivas. Alinhando-se a esse discurso, e sistematizando as ideias, Dourado e Oliveira (2009) condicionam a qualidade da educação a fatores intra e extraescolares. Considerando apenas os fatores intraescolares, os autores apontam para a existência de quatro grupos distintos, porém, interdependentes, quais

\footnotetext{
${ }^{1}$ O SPAECE é uma avaliação externa em larga escala que avalia as competências e habilidades dos alunos da Educação Básica, dos Sistemas Públicos de Ensinos municipais e estaduais do Ceará.
} 
sejam: o plano do sistema, plano de escola, plano do professor e plano do aluno. O primeiro, em especial, diz respeito às condições de oferta do ensino referindo-se, de modo geral, à garantia de instalações acessivelmente adequadas em quantidade e qualidade, considerando aspectos estruturais, pedagógicos, humanos e técnicos.

Em uma pesquisa realizada entre os anos de 2011 e 2014, com 18 escolas, da Mesorregião Oeste de Santa Catarina, intitulada "Indicadores de Qualidade do Ensino Fundamental na Mesorregião de Santa Catarina: estratégias e ações em prol da qualidade da educação (2010-2014)", tratou de identificar quais fatores podem ser associados à qualidade educacional, considerando a visão dos gestores escolares, identificou que as condições físicas e os recursos pedagógicos estão no topo das ações de interesse à melhoria da oferta educacional, observadas ante o crescimento dos indicadores educacionais oriundos das avaliações externas, em especial o IDEB.

Para o aspecto das condições físicas, na pesquisa acima citada, foi pontuada a necessidade de ampliar a estrutura física com a construção de salas de aula, ginásio poliesportivo e biblioteca; instalar laboratório de informática; criar salas multifuncionais; adquirir mobiliário; reformar o prédio escolar; e adquirir equipamentos eletrodomésticos. No que concerne o aspecto recursos pedagógicos, foi indicada a aquisição de material didático pedagógico; adquirir material didático-apostilado; adquirir equipamentos pedagógicos de apoio; viabilizar instalação de internet; e ampliar o acervo da biblioteca (Rios \& Trevisol, 2015). Essa necessidade se fundamenta por meio das palavras de Satyro \& Soares (2007, p. 7), quando, ao tratarem como insumos, advogam que

A infraestrutura escolar pode exercer influência significativa sobre a qualidade da educação. Prédios e instalações adequadas, existência de biblioteca escolar, espaços esportivos e laboratórios, acesso a livros didáticos, materiais de leitura e pedagógicos, relação adequada entre o número de alunos e o professor na sala de aula e maior tempo efetivo de aula, por exemplo, possivelmente melhorem o desempenho dos alunos.

Devemos concordar que tais afirmações encontram suporte também na experiência docente de todo profissional da educação, inclusive, sabendo que a escola, depois da família, é o ambiente de aprendizagem social, que funciona como modelo e, posteriormente, meio de comparação contestatária, aos olhos das crianças (Malik, 2003). Sua negação se tornaria incoerente ante constantes reestruturações e modernização dos processos de ensino, presentes na sociedade e necessárias a uma prática pedagógica inovadora. É imprescindível que a promoção da educação seja concebida em ambientes estruturais estimulantes e favoráveis à 
aquisição da aprendizagem, bem como as interações humanas. (Soares Neto, Jesus, Karino \& Andrade, 2013, p. 78).

Ademais, tomando como base a importância de estruturas que concedam a equidade na educação como fator preponderante da qualidade, ao tempo que observa-se a realidade brasileira, de acordo com os autores acima, torna-se evidente "a necessidade de políticas públicas que visem a diminuir as discrepâncias e promover condições escolares mínimas para que a aprendizagem possa ocorrer em um ambiente escolar mais favorável”. (Soares Neto et al., 2013, p. 97).

Portanto, no contexto educacional, as relações existentes entre estrutura física e qualidade se apresentam como fatores quase que intrínsecos à oferta do ensino de qualidade. Por outro lado, a crença nesse modelo pode evidenciar que sua inexistência possa ser o motivo da existência do fracasso escolar. É essa afirmação que torna ainda mais necessária a pesquisa ora proposta.

\section{Metodologia}

O estudo foi construído entre os anos de 2018 e 2020, em 10 EEEP's, distribuídas em 8 municípios de distintas regiões de planejamento do Estado do Ceará, considerando a divisão por Coordenadorias Regionais de Desenvolvimento da Educação (CREDE) e Superintendência das Escolas Estaduais de Fortaleza (SEFOR).

Trata-se de um trabalho de natureza qualitativa, com cunho descritivo, na forma de um estudo comparativo feito por meio de: levantamento bibliográfico, pesquisa documental, observação in loco e aplicação de questionário.

Consoante Rossman \& Rallis (1998 como citado em Creswell, 2007, p. 186), na pesquisa qualitativa o pesquisador pode "desenvolver um nível de detalhes sobre a pessoa ou sobre o local e estar altamente envolvido nas experiências reais dos participantes", podendo utilizar um ou mais meios investigativos. É relevante ressaltar que essa natureza de pesquisa

É fundamentalmente interpretativa. Isso significa que o pesquisador faz uma interpretação dos dados. Isso inclui o desenvolvimento de descrição de uma pessoa ou de um cenário, análise de dados para identificar temas ou categorias e finalmente, fazer uma interpretação ou tirar conclusões sobre seu significado, pessoal e teoricamente, mencionando as lições aprendidas e oferecendo mais perguntas a serem feitas (Ibid, 2007, p. 186). 
Quanto a tipologia descritiva, para Triviños (1987) e Gil (2008), possui como objetivos essenciais a descrição das características de determinada população ou acontecimento ou, ainda, o estabelecimento de afinidades entre variáveis. Esses autores afirmam que algumas das particularidades desse tipo de pesquisa dar-se-á pelo emprego de técnicas padronizadas para obtenção dos dados.

Ademais, de acordo com Rudio (2014, p. 71- 72), a pesquisa descritiva preocupa-se em descobrir e observar acontecimentos, podendo aparecer em formas de pesquisa documental, estudo de caso, entre outras. Segundo o autor,

Estudando o fenômeno, a pesquisa descritiva deseja conhecer a sua natureza, sua composição, processos que o constituem ou nele se realizam. . . . O problema será enunciado em termos de indagar se o fenômeno acontece ou não, que variáveis o constituem, como classificá-lo, que semelhanças ou diferenças existem entre determinados fenômenos, etc. Os dados obtidos devem ser analisados e interpretados e podem ser qualitativos, utilizando-se palavras para descrever o fenômeno (p. 71).

Considerando os procedimentos técnicos, fizemos um levantamento bibliográfico que possui como principal objetivo "colocar o pesquisador em contato direto com tudo o que foi escrito, dito ou filmado sobre determinado assunto" (Marconi \& Lakatos, 2003, p. 183), sendo de essencial importância ao pesquisador no "reforço paralelo nas análises de suas pesquisas ou manipulação de suas informações”. (Trujillo, 1974, p. 230 como citado em Marconi \& Lakatos, 2003, p. 183).

A pesquisa documental foi utilizada para fortificar a fundamentação do trabalho e desenvolvimento da metodologia. Esse tipo de pesquisa se caracteriza pelas fontes do levantamento de informações restringirem-se a documentos, escritos ou não, estabelecendo a ideia de fontes primárias (Ibidem).

Quanto a observação in loco, avaliou aspectos, tais como: salas de aula; laboratórios; biblioteca e sala de leitura; equipamentos de lazer, esportes cultura e arte; e auditório. Nesse contexto, a observação nos possibilitou "identificar e a obter provas a respeito de objetivos sobre os quais os indivíduos não têm consciência, mas que orientam seu comportamento" (Ibidem, p. 191).

Por fim, o questionário foi construído como forma de identificação dos ambientes e instrumentos didático-pedagógicos escolares disponíveis em quantidade, qualidade e conservação. Ele continha perguntas abertas e fechadas e a base para formulação foram os instrumentos contextuais da Prova Brasil. 
Considerando o tipo de pesquisa, como forma de organização, a exposição, análise e entendimento dos resultados foram feitos de forma separadas, considerando escolas de alto e baixo rendimento.

\subsection{Seleção da amostra da pesquisa}

Para definir escolas de alto e baixo rendimento, utilizamos os resultados obtidos por meio das avaliações do SPAECE. Inicialmente houve um levantamento de todas as EEEP's que realizaram essa avaliação nos anos de 2012, 2013, 2014, 2016 e 2017, de acordo com planilha disponibilizada pela SEDUC.

Tabela 1 - Quantitativo de escolas que realizaram o SPAECE - 2012/2017.

\begin{tabular}{l|ccccc}
\hline ANO & $\mathbf{2 0 1 2}$ & $\mathbf{2 0 1 3}$ & $\mathbf{2 0 1 4}$ & $\mathbf{2 0 1 6}$ & $\mathbf{2 0 1 7}$ \\
\hline QUANTIDADE & 59 & 77 & 92 & 106 & 113 \\
\hline
\end{tabular}

Fonte: Elaboração própria com dados disponibilizados pela SEDUC/CE (2018).

Com o quantitativo de escolas e os resultados individuais, construiu-se um ranking composto pelos resultados obtidos na avaliação de matemática ${ }^{3}$. Após isso, houve a seleção da amostra, considerando apenas as dez primeiras e as dez últimas posições de cada ano. Para isso, foram usados os seguintes critérios:

a) Escolas com notas mais altas: aparecer, no mínimo, quatro vezes entre os dez primeiros lugares nos anos observados;

b) Escolas com notas mais baixas: aparecer, no mínimo, três vezes entre os dez primeiros lugares nos anos observados.

Dessa forma, foram selecionadas 5 escolas com resultados mais altos e 5 com menores resultados. No sentido de preservar a identidade das instituições, optou-se identifica-las por meio de um código alfa numérico com combinação entre as iniciais do nome da escola e do município que elas se encontram, iniciando com o numeral 1 para aquelas consideradas de alto rendimento e o numeral 2 para as de baixo rendimento. Para melhor exemplificação, foi construída a Figura 1 com os resultados de cada uma no SPAECE.

\footnotetext{
${ }^{2}$ No ano de 2015 não houve aplicação de avaliações do SPAECE para as turmas de ensino médio.

${ }^{3}$ A justificativa para utilização dos resultados da disciplina de matemática partiu do pressuposto da necessidade imprescindível do aluno possuir conhecimentos em língua portuguesa para resolução das questões matemáticas, visto que, ante os modelos de questões do instrumento avaliativo, percebe-se a presença constante de leitura e interpretação de problemas.
} 
Figura 1 - Resultados das escolas com notas altas e baixas no SPAECE 2012, 2013, 2014, 2016 e 2017, considerando a escala de proficiência ${ }^{4}$.

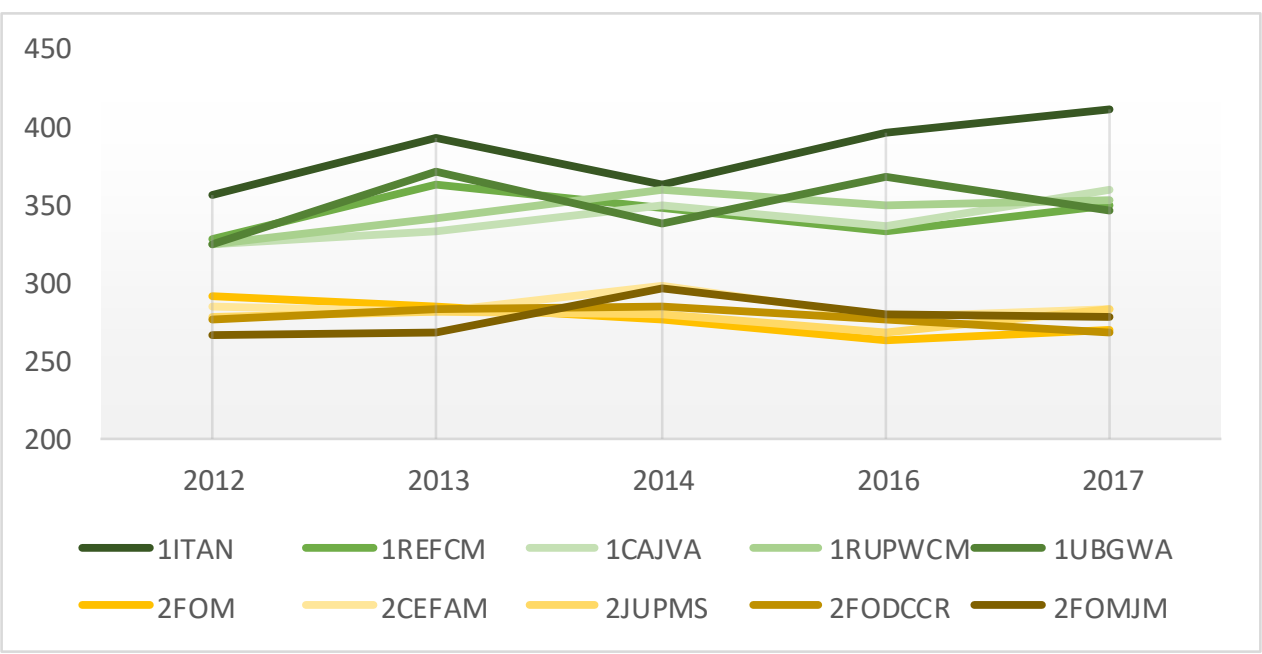

Fonte: Elaboração própria com dados disponibilizados pela SEDUC/CE (2018).

As 5 instituições de alto rendimento estão localizadas na $2^{\circ}$ CREDE/Itapipoca (1 escola), $5^{\circ}$ CREDE/Tianguá (1), $6^{\circ} \mathrm{CREDE} /$ Sobral (1), $7^{\circ} \mathrm{CREDE} / \mathrm{Canindé} \mathrm{(1),} \mathrm{e} 10^{\circ}$ CREDE/Russas (1). Já as 5 de baixo rendimento estão na $17^{\circ}$ CREDE/Icó (1), $19^{\circ}$ CREDE/Juazeiro do Norte (1), SEFOR I (2) e SEFOR II (1). O Estado do Ceará é dividido em 20 CREDE's mais Fortaleza, que é dividida em 3 SEFOR's.

\section{Resultados e Discussão}

Foi construído um questionário no qual deveriam ser indicados estruturas, ambientes, equipamentos e recursos existentes na escola, que contribuem de forma direta ou não à aprendizagem dos estudantes, identificando, inclusive, suas condições de uso. Além disso, foi construído um roteiro de observação que pudesse confirmar ou complementar os aspectos e características desse formulário.

\subsection{Escolas de alto rendimento}

Considerando que os resultados utilizados como critérios para a escolha das escolas que fariam parte do estudo foram datados até 2017, estruturalmente, todas as instituições eram adaptadas, portanto, não se enquadrando no modelo padrão de escola profissional indicada

4 O SPAECE utiliza uma escala de proficiência exemplificada por meio valores, cores e conceitos: desejável=verde escuro=acima de 350; intermediário=verde claro=300 a 350; crítico=amarelo=250 a 300; muito crítico=vermelho=até 250 . 
Research, Society and Development, v. 9, n. 7, e642974634, 2020

(CC BY 4.0) | ISSN 2525-3409 | DOI: http://dx.doi.org/10.33448/rsd-v9i7.4634

pelo Ministério da Educação $(\mathrm{MEC})^{5}$. Todavia, a coleta de dados dessa pesquisa aconteceu após duas escolas desse grupo já terem sido mudadas para prédios novos, que estão em conformidade ao modelo estabelecido para a oferta de educação profissional de nível médio em tempo integral. Logo, em momentos pontuais, a comparação com o outro grupo, se considerado apenas as respostas do questionário, pode não representar a alternativa mais viável, afastando-se da fidedignidade do estudo, o que fortifica a necessidade de intercalar com a observação.

A Tabela 2 de resultados a seguir, considera o quantitativo de escolas que informaram sobre a existência e estado de conservação de partes estruturais do prédio, essenciais ao seu funcionamento.

Tabela 2 - Quanto à existência e estado de conservação dos itens e equipamentos abaixo (por quantidade escola).

\begin{tabular}{|c|c|c|c|c|}
\hline & BOM & REGULAR & RUIM & INEXISTENTE \\
\hline TELHADO & 4 & 1 & & \\
\hline PAREDES & 3 & 2 & & \\
\hline PISO & 5 & & & \\
\hline CORREDORES & 5 & & & \\
\hline PORTAS & 3 & 2 & & \\
\hline JANELAS & 3 & 1 & & 1 \\
\hline BANHEIRO & 3 & 2 & & \\
\hline COZINHA & 4 & 1 & & \\
\hline REFEITÓRIO & 2 & & & 3 \\
\hline DIRETORIA & 4 & 1 & & \\
\hline SECRETARIA ESCOLAR & 5 & & & \\
\hline SALA DOS PROFESSORES & 4 & 1 & & \\
\hline SALA DE AULA & 4 & 1 & & \\
\hline BIBLIOTECA & 3 & 1 & & 1 \\
\hline SALA DE LEITURA & 3 & 1 & & 1 \\
\hline SALA DE AEE & & & & 5 \\
\hline AUDITÓRIO & 3 & & & 2 \\
\hline LABORATÓRIO DE INFORMÁTICA & 2 & 2 & 1 & \\
\hline LABORATÓRIO DE CIÊNCIAS & 3 & 2 & & \\
\hline SALA DE JOGOS & 2 & & 1 & 2 \\
\hline QUADRA DE ESPORTES & 3 & 1 & 1 & \\
\hline ÁREAS DE LAZER AO AR LIVRE & 2 & 1 & 1 & 1 \\
\hline ESTACIONAMENTO & 2 & & 1 & 2 \\
\hline INSTALAÇÕES HIDRÁULICAS & 3 & 1 & 1 & \\
\hline INSTALAÇÕES ELÉTRICAS & 3 & 2 & & \\
\hline
\end{tabular}

Fonte: Da pesquisa (2020).

\footnotetext{
${ }^{5} \mathrm{O}$ programa fortalecimento do ensino médio integrado à educação profissional nas redes estaduais de educação profissional, instituído no ano de 2007, com respaldo na Lei $n^{\circ} 11.741$ que alterou dispositivos da LDB, prevê a construção, reforma e modernização de escolas técnicas e estruturação de laboratórios, por meio de apoio financeiro e técnico, para adequação às demandas da oferta de ensino com qualidade. As escolas que passam por essa modernização ou são construídas com esse viés arquitetônico, se enquadram ao que comumente chamam de "escola padrão MEC".
} 
Identificamos que a maioria dos pontos foi marcada como existente e em bom estado de conservação, no entanto, é de fácil percepção a ausência ou a má condição de uso dos equipamentos em ambientes abertos ou de uso comum por toda a escola, tais como: quadra de esportes, auditório, refeitório, sala de jogos, sala de leitura, laboratório de informática e estacionamento. Essa ausência pode ocasionar deficiências na oferta de uma educação de qualidade, uma vez que a infraestrutura representa significativas influências no contexto geral da instituição (Satyro \& Soares, 2007). Além disso, destaca-se em todas as escolas a inexistência do espaço destinado ao Atendimento Educacional Especializado (AEE).

A observação das deficiências ou ausências desses espaços, especificamente, mostram a falta de conformidade das instituições à oferta do ensino integral, agravando-se por tratarem-se de oferta de educação profissional integrada ao nível médio. Esses fatores serão vistos de forma mais agravante no grupo de baixo rendimento. Lembrando mais uma vez que duas dessas escolas, no período da visita, já estavam no padrão exigido pelo MEC.

Ainda sobre os espaços, questionamos especificamente sobre as estruturas das salas de aula, tendo em vista ser o principal ambiente de trabalho efetivo do professor com os alunos, no qual eles passam a maior parte do tempo quando estão na escola.

Figura $2^{6}$ - Sobre as condições das salas de aula.

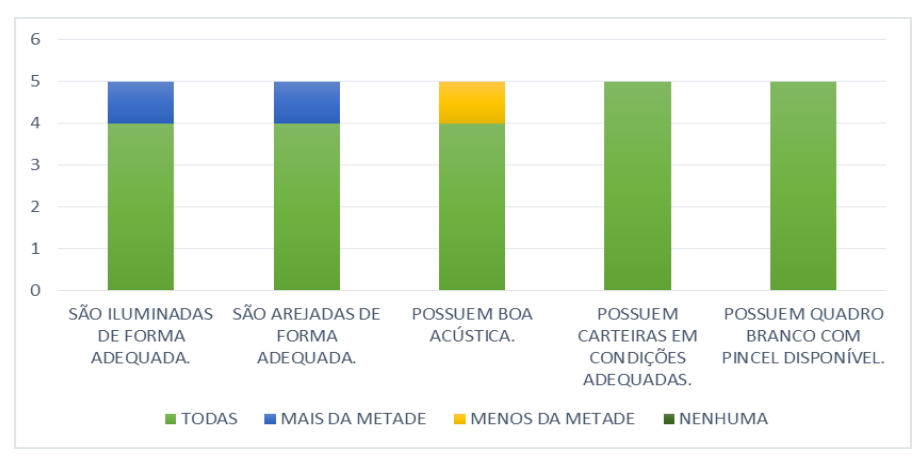

Fonte: Da pesquisa (2020).

Nota-se que o resultado foi bastante positivo para os pontos sobre qualidade da iluminação e a circulação do ar, pois todas as escolas informaram ser boa, com exceção de uma em cada ponto, que disse que nem todas as salas eram assim. Quanto à boa acústica, quatro escolas disseram que sim e uma informou ter em menos da metade das salas. Já em relação a possuir quadro branco, pincel disponível e as cadeiras terem condições adequadas de uso, as respostas foram todas positivas.

\footnotetext{
${ }^{6}$ Gráficos nesse formato são de frequência, ou seja, todas as escolas pontuam em todas as opções. Cada coluna do gráfico representa o total de escolas.
} 
Research, Society and Development, v. 9, n. 7, e642974634, 2020

(CC BY 4.0) | ISSN 2525-3409 | DOI: http://dx.doi.org/10.33448/rsd-v9i7.4634

Os resultados a seguir pautam recursos tecnológicos disponíveis à escola como um todo, para uso dos professores como recurso pedagógico ao desenvolvimento da prática pedagógica e para uso dos alunos.

Tabela 3 - Quanto à existência e estados dos recursos apontados abaixo (por quantidade escola).

\begin{tabular}{|c|c|c|c|c|}
\hline & BOM & REGULAR & RUIM & INEXISTENTE \\
\hline COMPUTADORES PARA USO DOS ALUNOS & 3 & 1 & 1 & \\
\hline $\begin{array}{l}\text { ACESSO À INTERNET PARA USO DOS } \\
\text { ALUNOS }\end{array}$ & 1 & 2 & 2 & \\
\hline $\begin{array}{l}\text { COMPUTADORES PARA USO DOS } \\
\text { PROFESSORES }\end{array}$ & 3 & 1 & & 1 \\
\hline $\begin{array}{l}\text { ACESSO À INTERNET PARA USO DOS } \\
\text { PROFESSORES }\end{array}$ & 2 & 3 & & \\
\hline $\begin{array}{l}\text { COMPUTADORES EXCLUSIVAMENTE PARA } \\
\text { USO ADMINISTRATIVO }\end{array}$ & 5 & & & \\
\hline IMPRESSORA & 5 & & & \\
\hline PROJETOR DE SLIDES/DATASHOW & 5 & & & \\
\hline TELEVISÃO & 5 & & & \\
\hline CÂMERA FOTOGRÁFICA & 3 & & & 2 \\
\hline INTERNET COM CONEXÃO BANDA LARGA & 1 & 2 & 2 & \\
\hline LINHA TELEFÔNICA & 2 & 2 & 1 & \\
\hline APARELHO DE SOM & 4 & 1 & & \\
\hline
\end{tabular}

Fonte: Da pesquisa (2020).

Os resultados foram expressivamente positivos, com ressalva àqueles relacionados ao acesso à comunicação e informação, que obtiveram algumas marcações negativas, como observado na tabela acima.

Tais recursos compõem o todo da estrutura escolar e devem ser alusivos à qualidade da oferta do ensino (Satyro \& Soares, 2007; Monteiro \& Silva, 2015). Especificamente, também foram realizados questionamentos acerca da estrutura, manutenção da biblioteca e ou sala de leitura.

Figura 3 - Sobre as condições da biblioteca ou sala de leitura.
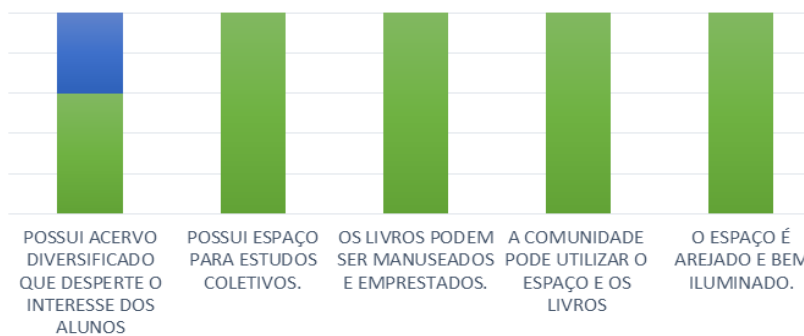
COLETIVOS. EEMPRESTADOS. AREADOE BEM 
Percebe-se que os resultados também foram positivos, com uma pequena observação de duas escolas que falaram sobre a falta de diversificação do acervo literário, considerando livros que despertem o interesse dos alunos. Além do questionário, isso também foi identificado nas observações in loco. Para finalizar, questionamos sobre possíveis sinais de depredação existentes na escola.

Figura 4 - Sobre sinais de depredações existentes na escola.

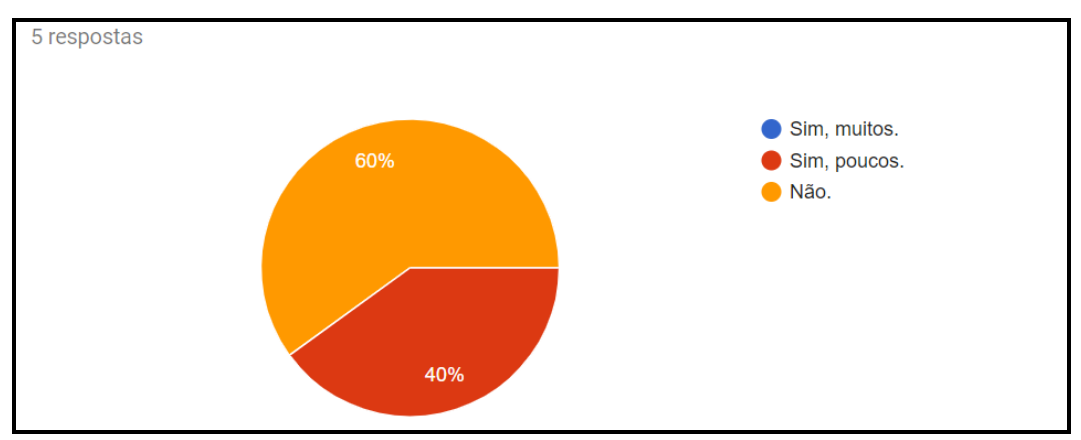

Fonte: Da pesquisa (2020).

Dentre as cinco instituições, 3 (60\%) informaram não haver sinais de depredação e 2 (40\%), disseram existir, porém, poucos.

Considerando as observações, de modo geral, as escolas não fogem à regra do que comumente se costuma perceber na maioria das instituições públicas de ensino, em relação a estrutura física e material disponível aos atores educacionais. Como discorre Malik (2003, p. 28), "a arquitetura escolar como forma de cultura transmite-nos uma visão estática da evolução humana na concepção prática como concebe espaço iguais para momentos iguais". No caso em questão, os ambientes dessas instituições existem suficientemente para proporcionarem seu funcionamento e os recursos disponíveis limitam-se as necessidades básicas dos sujeitos.

\subsection{Escolas de baixo rendimento}

Assim como no grupo de escolas de alto rendimento, até 2017, data limite utilizada para seleção da amostra, todas as instituições deste grupo tinham seus prédios adaptados, destarte, não se enquadrando dentro do modelo padrão de escola profissional indicado pelo MEC. Não obstante, diferentemente do outro grupo, no momento da coleta de dados esse não tinha nenhuma instituição em prédio novo, conforme modelo estabelecido para a oferta desse tipo de ensino. 
São apresentados a seguir os resultados obtidos sobre a existência e estado de conservação de ambientes e partes da estrutura dos prédios.

Tabela 4 - Quanto à existência e estado de conservação dos itens e equipamentos abaixo (por quantidade escola).

\begin{tabular}{|c|c|c|c|c|}
\hline & BOM & REGULAR & RUIM & INEXISTENTE \\
\hline TELHADO & 2 & 1 & 2 & \\
\hline PAREDES & & 3 & 2 & \\
\hline PISO & 2 & 1 & 2 & \\
\hline CORREDORES & 3 & 2 & & \\
\hline PORTAS & & 2 & 3 & \\
\hline JANELAS & & & 2 & 3 \\
\hline BANHEIRO & & 4 & 1 & \\
\hline COZINHA & 2 & 3 & & \\
\hline REFEITÓRIO & & & & 5 \\
\hline DIRETORIA & 5 & & & \\
\hline SECRETARIA ESCOLAR & 5 & & & \\
\hline SALA DOS PROFESSORES & 1 & 3 & 1 & \\
\hline SALA DE AULA & 1 & 1 & 3 & \\
\hline BIBLIOTECA & 4 & 1 & & \\
\hline SALA DE LEITURA & 1 & & & 4 \\
\hline SALA DE AEE & & & & 5 \\
\hline AUDITÓRIO & 1 & 2 & 1 & 1 \\
\hline LABORATÓRIO DE INFORMÁTICA & 2 & 3 & & \\
\hline LABORATÓRIO DE CIÊNCIAS & 4 & 1 & & \\
\hline SALA DE JOGOS & & & & 5 \\
\hline QUADRA DE ESPORTES & 1 & 3 & 1 & \\
\hline ÁREAS DE LAZER AO AR LIVRE & 2 & 1 & 1 & 1 \\
\hline ESTACIONAMENTO & 1 & 3 & & 1 \\
\hline INSTALAÇÕES HIDRÁULICAS & 1 & 2 & 2 & \\
\hline INSTALAÇÕES ELÉTRICAS & & 2 & 3 & \\
\hline
\end{tabular}

Fonte: Da pesquisa (2020).

Em uma visão geral, percebe-se que não existe uniformidade nas respostas obtidas que pudessem caracterizar um perfil padrão escolar para esse grupo. Muitos pontos foram marcados como bons, mas também foram observadas classificações regulares, ruins e até inexistentes. Nenhuma das escolas possui sala de AEE para apoio ao estudante com necessidades educacionais especiais, refeitório e sala de jogos, ambientes necessários ao convívio social, por se tratarem de escolas em tempo integral. Inclusive, a ausência de sala de leitura, ambientes ao ar livre e auditório em algumas escolas chama bastante atenção.

Espaços tidos como essenciais ao desenvolvimento do processo de ensino aprendizagem, ou estruturas desse espaço, tais como sala de aula, paredes, piso, telhado, instalações elétricas e hidráulicas, também foram pontuadas de forma negativa, considerando a má condição de uso. 
Percebendo o exposto sobre as salas de aula na tabela acima, em que apenas uma escola disse que possuíam boas condições de uso, vale observar, especificamente, o que se refere a isso. Abaixo são apontadas as condições exclusivas das salas de aula.

Figura 5 - Sobre as condições das salas de aula.

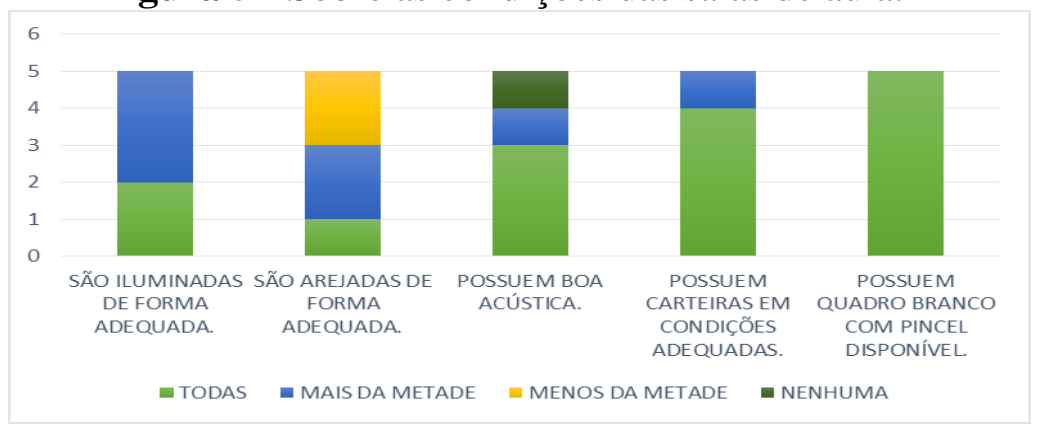

Fonte: Da pesquisa (2020).

Considerando as respostas na Figura 5, algumas escolas apontaram que as salas de aula não eram iluminadas de forma adequada, não eram bem arejadas, não possuíam boa acústica (uma delas informou que nenhuma sala possuía) e que algumas tinham carteiras em condições inadequadas de uso. Todas confirmaram a existência de pincel e quadro branco disponível. No que concerne esse ambiente, Monteiro \& Silva (2015, p. 28) preconizam que

É o principal espaço escolar que deve ser estruturado para o desenvolvimento das atividades escolares, pois é nela onde acontecem as principais relações do ensinar e do aprender. Se não há uma boa sala de aula, que ofereça as mínimas condições de comodidade, tanto para o aluno quanto para o professor, esse processo será defasado.

Os recursos tecnológicos disponíveis à escola, tanto para uso pelo professores e alunos, bem como nos setores administrativos, foram pontuados na tabela a seguir. 
Research, Society and Development, v. 9, n. 7, e642974634, 2020

(CC BY 4.0) | ISSN 2525-3409 | DOI: http://dx.doi.org/10.33448/rsd-v9i7.4634

Tabela 5 - Quanto à existência e estados dos recursos apontados abaixo (por quantidade escola).

\begin{tabular}{l|c|c|c|c}
\hline & BOM & REGULAR & RUIM & INEXISTENTE \\
\hline COMPUTADORES PARA USO DOS ALUNOS & & 4 & 1 & \\
ACESSO À INTERNET PARA USO DOS ALUNOS & 2 & 2 & 1 & \\
COMPUTADORES PARA USO DOS & 1 & 3 & 1 & \\
PROFESSORES & 2 & 1 & 2 & \\
ACESSO À INTERNET PARA USO DOS & & & & \\
PROFESSORES & 5 & & \\
COMPUTADORES EXCLUSIVAMENTE PARA & & & & \\
USO ADMINISTRATIVO & 5 & & & \\
IMPRESSORA & 5 & & \\
PROJETOR DE SLIDES/DATASHOW & 4 & 1 & & 1 \\
TELEVISÃO. & 4 & & 1 & 1 \\
CÂMERA FOTOGRÁFICA & 3 & & 2 & \\
INTERNET COM CONEXÃO BANDA LARGA & 2 & 1 & & \\
LINHA TELEFONICA & 4 & & \\
APARELHO DE SOM &
\end{tabular}

Fonte: Da pesquisa (2020).

Os resultados são semelhantes aos do grupo de escolas de alto rendimento, maior expressividade positiva, com a mesma ressalva aos itens que dizem respeito às conexões com a internet, para acesso a comunicação e informação.

Os dois próximos gráficos consistem nos aspectos relacionados ao acesso, manutenção e estruturação da biblioteca e/ou sala de leitura. Observe.

Figura 6 - Sobre as condições da biblioteca ou sala de leitura.
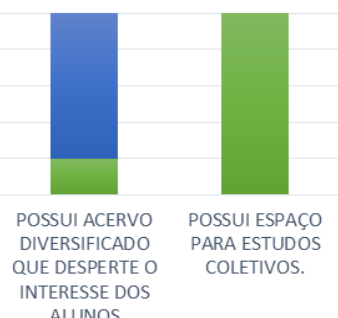

COLETIVOS.

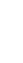

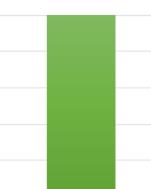

OSLIVROS PODEM A COMUNIDADE SER MANUSEADOS PODE UTILIZAR O EMPRESTADOS LIVROS

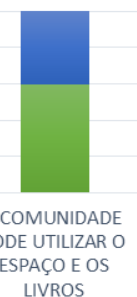

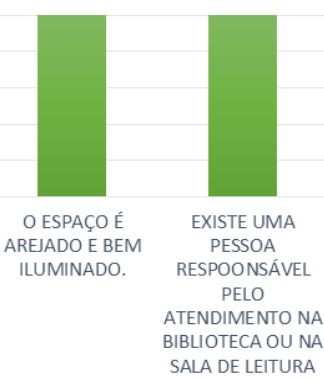
SALA DE LEITURA

= SIM NÃO = NÃO HÁ BIBLIOTECA/SALA DE LEITURA

Fonte: Da pesquisa (2020).

Observando o gráfico acima, o que chama mais atenção é o fato de quatro das cinco escolas denunciarem a falta de livros no acervo, que possam despertar o interesse dos alunos, fato esse confirmado nas observações. A predominância dos acervos, inclusive nas escolas do grupo de alto rendimento, se constitui predominantemente de livros didáticos ou com temáticas ultrapassadas. 
Research, Society and Development, v. 9, n. 7, e642974634, 2020

(CC BY 4.0) | ISSN 2525-3409 | DOI: http://dx.doi.org/10.33448/rsd-v9i7.4634

Sobre possíveis sinais de depredação de pontos específicos das estruturas físicas da escola, de acordo com a Figura 7, foram identificadas as seguintes respostas.

Figura 7 - Sobre sinais de depredações existentes na escola.

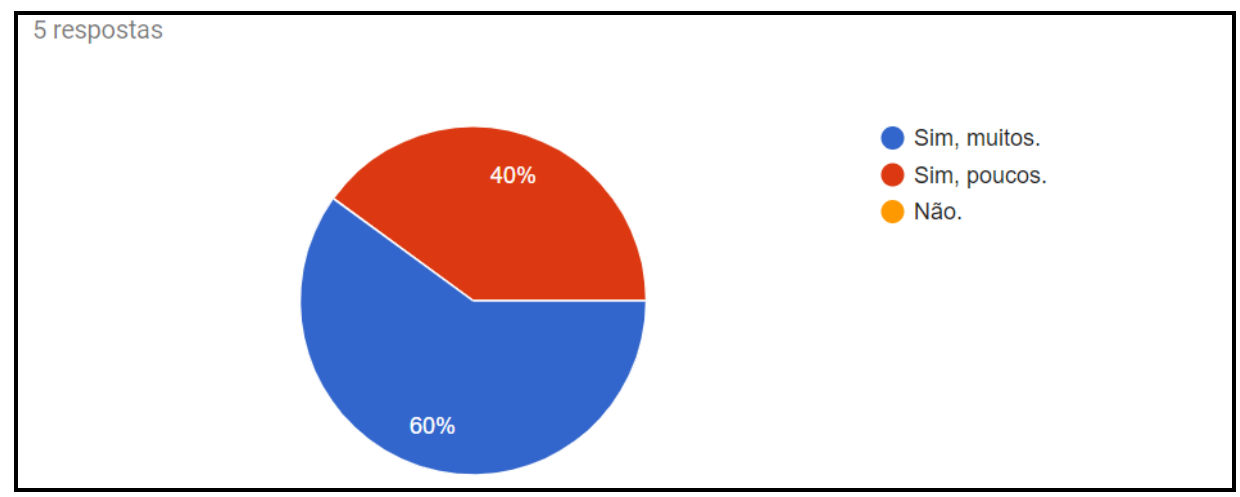

Fonte: Da pesquisa (2020).

Das cinco escolas e diferentemente do grupo de alto rendimento, $3(60 \%)$ informaram haver muitos sinais de depredação, e 2 (40\%), disseram existir, porém, poucos. De acordo com Monteiro \& Silva (2015, p. 28), "uma escola necessita de instalações e materiais de qualidade, pois o processo de ensino-aprendizagem é muito complexo", sendo necessário, inclusive, "que se adotem políticas públicas que deem subsídios para as escolas se manterem" (Ibid, p. 28). É importante destacar que esses sinais de depredação, nas observações, foram identificados em alguns ambientes, no entanto, a maior percepção foi falta de manutenção, limpeza e organização dos espaços e estruturas.

\section{Considerações Finais}

No trabalho ora apresentado propomos avaliar se a estrutura física escolar, além de recursos didático-pedagógicos disponíveis, se comportam como fatores determinante ao alcance da qualidade educacional. Logo, realizamos um estudo comparativo entre 10 Escolas de Educação Profissional do Estado do Ceará, sendo 5 com alto e 5 com baixo rendimento, considerando os resultados das avaliações realizadas no âmbito do SPAECE. Inicialmente fizemos uma breve discussão teórica e documental acerca da estrutura física escolar e sua relação com a qualidade na oferta do ensino. Em seguida realizamos uma coleta de dados com a utilização de distintos instrumentos, para que posteriormente fosse realizado um estudo comparativo entre as instituições, etapa essa observado nos resultados. 
Ante os resultados, ficou evidente que a grande maioria dos fatores positivos - e até mesmo negativos - está presente nas escolas dos dois grupos. Todavia, considerando a realidade das instituições, as quais se dividem entre alto e baixo rendimento, é possível que se observados em um contexto mais amplo e na existência de outros fatores, esses pontos possam se tornar ineficazes ou nulos, ao serem tratados de forma isolada e não se interligarem na constituição de unidade dentro da instituição.

Revendo a extensa literatura educacional que destaca a oferta do ensino, é fácil identificar a qualidade como fator dependente à estrutura física dos prédios e ao material pedagógico disponível nas instituições escolares. De fato, isso é algo incontestável, e concordamos com tais apontamentos. Todavia, torna-se incoerente justificar o insucesso escolar através de um único determinante, uma vez que o ensino e a aprendizagem possuem uma multiplicidade de dimensões, que devem ser consideradas nos percursos formativos dos sujeitos, tais como gestão, formação de professores, projeto político pedagógico, trabalho docente, currículo, avaliação, dentre outros.

Isso se confirma tendo como base os resultados obtidos nesse estudo que apontam a estrutura da instituição escolar, bem como os materiais de uso pedagógico, como contribuinte para aquisição de resultados positivos, porém, que não se sobressaem considerando os dados obtidos e analisados no estudo comparativo, tendo em vista que a realidade de um grupo não se distancia do outro grupo. Isso permite acreditar que a indicação desse fator, por ser mais palpável, visível aos olhos e não contestar a posição que ocupa, configura-se como motivo fácil de ser incluído em uma possível justificativa aos baixos resultados educacionais, o que pode ser observado em diversos estudos, como os pontuados na fundamentação desse artigo, que relacionam estrutura física escolar e qualidade.

De forma conclusiva, esse estudo descarta o fator estrutura física, porém, de forma isolada, como fator determinante da oferta da educação de qualidade, bem como propulsor do sucesso escolar, que considera resultados de avaliações externas. Ademais, se apresenta como imensurável contribuição à formação acadêmica, científica e profissional, ao tempo que concebe aportes teóricos à construção de novas pesquisas de melhoria da aprendizagem estudantil.

\section{Referências}

Creswell JW (2007). Projeto de pesquisa: métodos qualitativos, quantitativos e erros. (2 ed.) . Porto Alegre: Artmed. 
Dourado LF \& Oliveira JF. (2009). A qualidade da educação: perspectivas e desafios. Cadernos Cedes, 29 (78), 201-215. Recuperado em 20 de fevereiro de 2020, em https://www.scielo.br/pdf/ccedes/v29n78/v29n78a04.pdf

Gil AC (2008). Como projetos de pesquisa elaborados. (6 ed.) . São Paulo: Atlas.

Kimura S. (2008). Geografia no ensino básico: questões e propostas. São Paulo: Contexto.

Lei no 9.394, de 20 de dezembro de 1996. Estabelece as diretrizes e bases da educação nacional. Diário Oficial da República Federativa do Brasil, Poder Executivo, Brasília, DF, 23 dez. 1996. Seção 1, p.1.

Malik LA (2003). Será uma escola facilitadora de aprendizagens?: o empenhamento na aprendizagem no ensino secundário. Lisboa: Fundação Calouste Gulbenkian: Fundação para a Ciência e a Tecnologia.

Marconi MA \& Lakatos EM (2003). Fundamentos de metodologia científica. (5 ed.). São Paulo: Atlas.

Monteiro JS \& Silva DP. (2015). A influência da estrutura escolar no processo de ensinoaprendizagem: uma análise baseada nas experiências do estágio supervisionado em Geografia. Geografia, Ensino \& Pesquisa, 19 (3), 19-28. Recuperado em 13 de maio de 2020, de https://periodicos.ufsm.br/geografia/article/viewFile/14315/pdf

Rios MPG \& Trevisol MTC. (2015) . Ações e estratégias para a qualidade da educação: uma leitura de gestores escolares. In Nardi, EL \& Schneider, MP (Coord), Qualidade da educação no ensino fundamental: entre políticas e a (ex)tensão do tema na escola pública (pp. 105130). Ijuí: Unijuí.

Rudio FV (2014). Introdução ao projeto de pesquisa científica. (42 ed.) . Petrópolis: Vozes. Satyro, N \& Soares, S. (2007). A infraestrutura das escolas brasileiras de ensino fundamental: um estudo com base nos censos escolares de 1997 a 2005. Brasília: IPEA. 
Soares Neto et al (2013). Uma escala para medir a infraestrutura escolar. Estudos em Avaliação Educacional, 24 (54), 78-99. Recuperado em 13 de maio de 2020, de http://www.fcc.org.br/pesquisa/publicacoes/eae/arquivos/1786/1786.pdf

Triviños ANS \& Soares S. (1987). Introdução à pesquisa em ciências sociais. São Paulo: Atlas.

Vieira SL \& Vidal EM. (2010). Gestão e sucesso escolar: visão de diretores versus indicadores. I Congresso Ibero-Luso-Brasileiro da Anpae (pp. 1-16). Recuperado em 15 de dezembro de 2019, de http://www.anpae.org.br/iberolusobrasileiro2010/cdrom/108.pdf.

\section{Porcentagem de contribuição de cada autor no manuscrito}

Lucas Melgaço da Silva - 50\%

Maria Isabel Filgueiras Lima Ciasca - 50\% 